\title{
Lateral Wall of the Pharynx
}

National Cancer Institute

\section{Source}

National Cancer Institute. Lateral Wall of the Pharynx. NCI Thesaurus. Code C129817.

The walls on either side of the swallowing passage. 